\title{
Numerical modeling of flow and morphology induced by a solitary wave on a sloping beach
}

\section{Li, Jinzhao; Qi, Meilan; Fuhrman, David R.}

\author{
Published in: \\ Applied Ocean Research
}

Link to article, DOI:

10.1016/j.apor.2018.11.007

Publication date:

2019

Document Version

Peer reviewed version

Link back to DTU Orbit

Citation (APA):

Li, J., Qi, M., \& Fuhrman, D. R. (2019). Numerical modeling of flow and morphology induced by a solitary wave on a sloping beach. Applied Ocean Research, 82, 259 - 273. https://doi.org/10.1016/j.apor.2018.11.007

\section{General rights}

Copyright and moral rights for the publications made accessible in the public portal are retained by the authors and/or other copyright owners and it is a condition of accessing publications that users recognise and abide by the legal requirements associated with these rights.

- Users may download and print one copy of any publication from the public portal for the purpose of private study or research.

- You may not further distribute the material or use it for any profit-making activity or commercial gain

- You may freely distribute the URL identifying the publication in the public portal 


\section{Numerical modeling of flow and morphology induced by a 2 solitary wave on a sloping beach}

3 Jinzhao Li ${ }^{\mathrm{a}, \mathrm{b}}$, Meilan $\mathrm{Qi}^{\mathrm{a}, \mathrm{d}^{*}}$, David R. Fuhrman ${ }^{\mathrm{c}}$

4

${ }^{a}$ Beijing Jiaotong University, School of Civil Engineering, Beijing 100044, China

${ }^{\mathrm{b}}$ National Engineering Laboratory of Port Hydraulic Construction Technology, Tianjin Research Institute of

$7 \quad$ Water Transport Engineering, Tianjin 300456, China

$8{ }^{\mathrm{c}}$ Technical University of Denmark, Department of Mechanical Engineering, Section of Fluid Mechanics,

9 Coastal and Maritime Engineering, DK-2800 Kgs. Lyngby, Denmark

10 dBeijing's Key Laboratory of Structural Wind Engineering and Urban Wind Environment, Beijing 100044,

11 China

$12 \quad{ }^{*}$ Corresponding author. E-mail address: mlqi@bjtu.edu.cn (M.L. Qi)

Abstract: A fully-coupled (hydrodynamic and morphologic) numerical model based on the open-source computational fluid dynamics (CFD) package OpenFOAM is presented and utilized to simulate flow and morphology induced by a solitary wave on a sloping beach. The hydrodynamic model is based on Reynolds-averaged Navier-Stokes (RANS) equations together with $k-\omega$ turbulence closure and volume of fluid (VOF) method for capturing the free surface. These are then coupled with both bed load and suspended load transport descriptions, which drive resultant morphology of the bed. The present numerical model is validated against a laboratory experiment of flow and morphological change induced by a solitary wave. The rigid-bed simulation illustrates that the numerical model can reasonably reproduce the characteristic sequences as observed in the experiment, including the wave shoaling, breaking, runup, rundown, hydraulic jump and trailing wave. The quantitative agreement between computed and measured results, including surface elevation, bed shear stress, and turbulent kinetic energy are satisfactory. The sediment-bed simulation demonstrates that the computed tendency of the bed profile evolution fits well with the measured results, showing the general pattern of both offshore deposition and onshore erosion. The deposition height is fairly well predicted, while the erosion depth is generally underestimated in the swash zone where the water depth is extremely thin. Overall, the results obtained from the present model are promising, especially considering the complexity of the coupled flow and morphological processes involved. beach 
As ocean waves propagate from the deep sea into coastal regions, due to water becoming shallow, the waves deform, shoal or even break during the process of wave evolution on sloping beaches. The wave-induced intensive flow can mobilize substantial amounts of sediment and produce significant erosion and morphological changes [1,2]. The resulting erosion can undermine pile foundations, offshore breakwaters, and other coastal structures [3-6]. Therefore, to ensure proper design in coastal engineering, it is crucial to improve the understanding and prediction of flow and related sediment transport process subjected to waves over sloping beaches.

Traditionally, solitary waves, as idealized wind-generated waves, are often utilized to model the waves in coastal area because of their shape similarities and underlying dynamic similarities [7-9]. Although the hydrodynamics within the propagation, runup, and rundown of solitary waves on sloping beaches have been extensively investigated (e.g. [10-13]), studies involving erosion and morphology exposed to solitary waves are comparatively rare $[2,14,15]$. Moreover, most relevant studies focus on surf zone processes, while swash zone investigations are quite limited (see the review by Briganti et al. [15]). The recent experimental study of Sumer et al. [16] inner surf and swash zones. They provided a detailed description of the entire sequence of wave evolution including shoaling, wave breaking, runup, rundown, hydraulic jump, and trailing waves, and especially on the resulting bed shear stress, sediment transport, and related morphological change. These experimental results are also valuable for the validation of numerical models. However, whether this complicated process involving solitary wave evolution, as well as resulting morphological change, can be well simulated by the modern numerical model is still unknown.

Most hydrodynamic models for wave modeling under deep-water conditions are based on potential flow theory with the assumption of irrotational and inviscid flow. However, in the coastal region where the water is relatively shallow and where wave shoaling or even breaking occurs, the contribution of viscous terms cannot be ignored [17], and thus potential flow models are not suitable. With the development of modern computational fluid dynamics (CFD) approaches, the RANS (Reynolds-averaged Navier-Stokes) equations based hydrodynamic model coupled with turbulence closure, as well as combining the free surface capturing method of VOF (volume of fluid), can be realized and applied in the simulation of wave propagation [18], breaking waves [19-21] or wave-structure interaction [22-25]. For example, Jacobsen, Fuhrman and Fredsøe developed the waves2Foam toolbox [26] based on the existing solver called interFoam in the open-source CFD package OpenFOAM. As a tool to help simulate waves, waves 2 Foam is becoming increasingly popular (see the discussion on the forum of "CFD Online"). This toolbox has been released online and made available freely [27], which is 
convenient for the researchers or engineers to freely download and use.

The numerical modeling of wave induced erosion process is a challenging task, which needs to properly couple hydrodynamic, sediment transport, and morphological models. Previous numerical models for predicting wave induced beach erosion or morphological change are mainly based on the depth-averaged shallow water equations [7,28]. These simple models are insufficient to properly simulate the complicated features involved in surf or swash zone dynamics such as wave breaking and intense turbulence. To date, the CFD based modeling of morphology under wave propagation and breaking in coastal regions appears to be quite limited. Recently, Jacobsen and Fredsøe [19] developed an advanced fully-coupled hydro- and morpho-dynamic model to simulate the breaking regular wave and resulting morphological change, while the swash zone is cut off in their modeling. However, the swash-zone hydrodynamics play important roles on sediment transport and morphological change, such as the thin-layer sheet flow with large bed shear velocity, which needs to be considered in the morphology modeling. Ahamad et al. [29] utilized the CFD model of REEF3D to simulate the breaking waves over a slope and the resulting erosion. Bakhtyar et al. [30] also developed a two-phase model to simulate the solitary wave breaking and sediment transport on the beach in the inner-surf and swash zones.

The motivation of the present work is to demonstrate the numerical modeling of flow and morphology induced by a solitary wave over a sloping bed including surf and swash zones, using an advanced fully-coupled hydrodynamic and morphologic CFD model based on the open-source CFD package OpenFOAM [31]. The remainder of this paper is organized as follows: The hydrodynamic model involving the free surface capturing method, turbulence closure, and wave generation are described in Section 2, which drives the sediment transport and morphological models described in Sections 3. The validation of the CFD model by comparing with the experiment of flow and morphology induced by a solitary wave on a sloping bed is presented in Section 4, including rigid-bed and sediment-bed cases. The summary and conclusions are finally drawn in Section 5.

\section{Hydrodynamic and turbulence models}

\subsection{Governing equations}

In the present study, the flow is simulated by solving the primitive incompressible Reynolds-averaged Navier-Stokes (RANS) equations

$$
\frac{\partial u_{i}}{\partial t}+u_{j} \frac{\partial u_{i}}{\partial x_{j}}=-\frac{1}{\rho} \frac{\partial p}{\partial x_{i}}+\frac{\partial}{x_{j}}\left[2 v S_{i j}+\frac{\tau_{i j}}{\rho}\right]+\frac{\sigma_{T} \kappa_{\gamma}}{\rho} \frac{\partial \gamma}{\partial x_{i}}
$$

where the mean-strain-rate tensor is 


$$
S_{i j}=\frac{1}{2}\left(\frac{\partial u_{i}}{\partial x_{j}}+\frac{\partial u_{j}}{\partial x_{i}}\right) .
$$

These are combined with the continuity equation

$$
\frac{\partial u_{i}}{\partial x_{i}}=0
$$

Here $u_{i}$ are the mean components of the velocities, $x_{i}$ are the Cartesian coordinates, $t$ is the time, $p$ is the pressure, $\rho$ is the fluid density, $v$ is the fluid kinematic viscosity, and $\tau_{i j}$ is the Reynolds stress tensor, which is expressed according to the Boussinesq approximation

$$
\tau_{i j}=-\overline{u_{i}^{\prime} u_{j}^{\prime}}=2 v_{T} S_{i j}-\frac{2}{3} k \delta_{i j},
$$

where $\delta_{i j}$ is the Kronecker delta, $v_{T}$ is the eddy viscosity,

$$
k=\frac{1}{2} \overline{u_{i}^{\prime} u_{i}^{\prime}},
$$

is the turbulent kinetic energy, and the overbar denotes time (ensemble) averaging. The last term in Eq. (1) is the effect of surface tension, where $\sigma_{T}$ is the surface tension coefficient, $\kappa_{\gamma}$ is the surface curvature, and $\gamma$ is the indicator representing the volume fraction, which takes a value 0 in air, 1 in water, and $0 \sim 1$ in an air-water mixture. In terms of $\gamma$, one can express the spatial variation in any fluid property, such as $\rho$ and $v$, through the weighting

$$
\varphi=\gamma \varphi_{\text {water }}+(1-\gamma) \varphi_{\text {air }}
$$

where $\varphi$ can be any such quantity.

For flow in river environments, the free surface variation is small and can often be regarded as a frictionless rigid-lid boundary [32]. In coastal regions, however, the free surface varies significantly due to the wave deformation, e.g. shoaling or even breaking, which needs to be accurately captured. The free surface is simulated by the volume of fluid (VOF) method [33], which can be descriped by the following equation:

$$
\frac{\partial \gamma}{\partial t}+\frac{\partial \gamma u_{j}}{\partial x_{j}}=0
$$

To achieve closure of the RANS equations, the $k$ - $\omega$ turbulence model by Wilcox [34,35] is adopted. In this model the eddy viscosity is defined by

$$
v_{T}=\frac{k}{\varpi}, \varpi=\max \left\{\omega, C_{l i m} \sqrt{\frac{2 S_{i j} S_{i j}}{\beta^{*}}}\right\},
$$
where $k$ is again the turbulent kinetic energy density and $\omega$ denotes the specific dissipation rate. This model also incorporates a stress limiting feature with $C_{\text {lim }}=7 / 8$. This model additionally utilizes the following transport equations for $k$ and $\omega$ : 


$$
\frac{\partial k}{\partial t}+u_{j} \frac{\partial k}{\partial x_{j}}=\frac{\tau_{i j}}{\rho} \frac{\partial u_{i}}{\partial x_{j}}-\beta^{*} k \omega+\frac{\partial}{\partial x_{j}}\left[\left(v+\sigma^{*} \frac{k}{\omega}\right) \frac{\partial k}{\partial x_{j}}\right],
$$

$$
\frac{\partial \omega}{\partial t}+u_{j} \frac{\partial \omega}{\partial x_{j}}=\alpha \frac{\omega}{k} \frac{\tau_{i j}}{\rho} \frac{\partial u_{i}}{\partial x_{j}}-\beta \omega^{2}+\frac{\sigma_{d}}{\omega} \frac{\partial k}{\partial x_{j}} \frac{\partial \omega}{\partial x_{j}}+\frac{\partial}{\partial x_{j}}\left[\left(v+\sigma \frac{k}{\omega}\right) \frac{\partial \omega}{\partial x_{j}}\right] .
$$

132 The following closure coefficients are used: $\alpha=0.52, \beta=0.078, \beta^{*}=0.09, \sigma=0.5, \sigma^{*}$ $=0.6, \sigma_{d o}=0.125$, and

$$
\sigma_{d}=H\left\{\frac{\partial k}{\partial x_{j}} \frac{\partial \omega}{\partial x_{j}}\right\} \sigma_{d o}
$$

where $H\{\cdot\}$ is the Heaviside step function, taking a value of zero if the argument is negative and unity otherwise.

\subsection{Wave generation}

In the present work, waves are generated utilizing the waves2Foam toolbox [26], and solitary waves are selected to model the process of wave transformation on a sloping beach. As the shape of solitary wave is reasonably similar to the wind-generated waves near the coast, it has been commonly used in studies related to coastal hydrodynamics. Based on the small-amplitude solitary wave theory, the free surface elevation $\eta$ can be expressed as

$$
\eta=H \operatorname{sech}^{2}\left[\sqrt{\frac{3 H}{4 h^{3}}}(x-c t)\right]
$$

where $H$ is the height of the solitary wave (measured from the still water level), $c$ is the wave celerity, defined as

$$
c=\sqrt{g(h+H)}
$$

where $h$ is the offshore water depth.

\section{Sediment transport and morphological models}

The sediment transport and morphological models are described in this section. The description will only include the most essential details since the implementation of the models have already been described and discussed in detail by Jacobsen et al. [31].

\subsection{Sediment transport model}

The sediment transport model consists of both bed load and suspended load sediment transport. The bed load sediment transport $q_{b}$ is calculated by the method of Roulund et al. [32], who extended the transport formulation of Engelund and Fredsøe [36] to account for bed slope modifications to the Shields parameter. The description will only include the most essential details since the implementation of the models have again already been described and discussed 
by Jacobsen et al. [31].

The suspended load is calculated by solving the advection-diffusion equation for the concentration (see e.g. p. 238 of Fredsøe and Deigaard [1]):

$$
\frac{\partial c}{\partial t}+\gamma\left(u_{j}-w_{s} \delta_{j 3}\right) \frac{\partial c}{\partial x_{j}}=\frac{\partial}{\partial x_{j}}\left[\gamma\left(v+\beta_{s} v_{T}\right) \frac{\partial c}{\partial x_{j}}\right],
$$

where $c$ is the suspended sediment concentration, the inverse of the Schmidt number $\beta_{s}=1$ is utilized i.e. the sediment diffusivity is taken as the same value of eddy viscosity, $w_{s}$ is the sediment settling velocity determined by the approach of Fredsøe and Deigaard [1], which is based on the drag coefficient of the falling sediment grains.

Equation (14) is solved on a sub-set of the main computational mesh where the near-bed cells below a given reference level $\delta_{b}$ are removed. Following the setting of Fuhrman et al. [37] and Larsen et al. [6], the reference level set as $\delta_{b}=\alpha_{1} d_{50}=3.5 d_{50}$, in which $d_{50}$ is the mean grain size. At this reference level a reference concentration, $c_{b}$, boundary condition is imposed, which is determined by the approach of Engelund and Fredsøe [1]:

$$
\begin{gathered}
c_{b}(\theta)=\frac{0.6}{\left(1+1 / \lambda_{b}\right)^{3}}, \\
\lambda_{b}^{2}=\frac{\kappa^{2} \alpha_{1}^{2}}{0.013 s \theta}\left(\theta-\theta_{c}-\frac{\pi}{6} \mu_{d} p_{E F}\right),
\end{gathered}
$$

where $\alpha_{1}$ is the multiplier of sediment diameter representing the height of the bed load transport (as define above). $s=\left(\rho_{s}-\rho\right) / \rho$ is the relative density of sediment, and $p_{E F}$ is the probability of moving particles near the bed, which is calculated by

$$
p_{E F}=\left[1+\left(\frac{\pi \mu_{d}}{6\left(\theta-\theta_{c}\right)}\right)^{4}\right]^{-1 / 4}
$$

where $\theta$ is the Shields number defined as

$$
\theta=\frac{\tau_{b}}{\rho g(s-1) d_{50}}=\frac{U_{f}^{2}}{(s-1) g d_{50}},
$$

where $\tau_{b}$ is the bed shear stress, and $U_{f}$ is the friction velocity. Throughout the present work the coefficient of dynamic friction is set to $\mu_{d}=0.7$ and the critical Shields parameter $\theta_{c}$ is calculated from a base value $\theta_{c 0}=0.05$, accounting for bed-slope effects as in Roulund et al. [32]. To prevent unphysical "overloading" conditions i.e. where the concentration just above the bed exceeds $c_{b}$ calculated from the reference concentration formula, the solution suggested by Justesen et al. [38] is invoked. That is, if the concentration close to the bed exceeds the reference concentration, the value is in practice taken from the cell adjacent to the boundary. 


\subsection{Morphological model}

The morphological change is computed based on the sediment continuity (Exner) equation:

$$
\frac{\partial h_{b}}{\partial t}=-\frac{1}{1-n}\left[\frac{\partial q_{b i}}{\partial x_{i}}+E_{s}+D_{s}\right], i=1,2
$$

where $h_{b}$ is the bed elevation, $n=0.4$ is the bed porosity. The right-hand terms in Eq. (19) represent the contributions from the bed load transport $\left(q_{b i}\right)$ and suspended load transport $\left(E_{s}\right.$ and $D_{s}$ ), where $E_{s}$ and $D_{s}$ are erosion and deposition respectively, calculated as

$$
\begin{gathered}
E_{s}=\left.\left(v+\beta_{s} v_{T}\right) \frac{\partial c}{\partial x_{3}}\right|_{x_{3}=\delta_{b}} \\
D_{s}=\left(w_{s}-u_{3}\right) c_{b}
\end{gathered}
$$

where $x_{3}$ and $u_{3}$ represent the position and velocity in vertical direction, respectively. The Exner equation is based on instantaneous sediment transport fields and therefore the morphological and hydrodynamic times are equivalent. To ensure that the bed slopes do not exceed the angle of repose, a sand slide model described in detail by Roulund et al. [32] is utilized. In the present work, this model is activated at positions where the local bed angle exceeds the angle of repose (= $32^{\circ}$ ), and is deactivated once the local bed angle has been reduced to $31.9^{\circ}$.

The equations comprising the fully-coupled model outlined above are solved numerically using the open-source CFD package OpenFOAM ${ }^{\circledR}$, version 1.6-ext, making use of a finite volume spatial discretization with a collocated variable arrangement, in conjunction with a standard PIMPLE algorithm. Again for further details the reader is referred to Jacobsen et al. [31]. The fully-coupled model described above has been utilized on several scour-related studies, including pipeline scour by Fuhrman et al. [37] and Larsen et al. [39], as well as local scour around a monopile by Baykal et al. [40,41] and Larsen et al. [6].

\section{Model validation}

In this section, the numerical model described above is tested and validated against the case of solitary wave induced flow and morphology over a sloping beach. In fact, the relevant references are limited. Sumer et al. [16] conducted an experiment regarding the flow and morphological induced by solitary waves on a sloping bed, which can be used to validate the present model.

\subsection{Validation case description}

The setup of the experiment is depicted in Fig. 1. The slope of the beach was 1/14, the offshore water depth was $h=0.40 \mathrm{~m}$, and the height of the solitary wave (measured from the still water level) was $H=0.071 \mathrm{~m}$. The sediment used in the test was approximately uniform with the 
217 grain size being $d_{50}=0.18 \mathrm{~mm}$ and the density being $2.6 \times 10^{3} \mathrm{~kg} \mathrm{~m}^{-3}$. The origin of the coordinate 218 system was defined at the still water surface above the slope toe, with the longitudinal $x$-axis 219 parallel to the flume bed and oriented to the onshore side, and the $y$-axis vertical normal to the 220 bottom of the flume. Detailed measurements were made at 8 sections. The locations of these sections are given in Fig. 1 and Table 1, with sections 1 4 located at the offshore side of the wave breaking, sections $5 \sim 8$ at the onshore side of the wave breaking, and sections $6 \sim 8$ being in the intermittently wet-dry area.

Two parallel experiments were conducted: (1) a rigid-bed experiment, allowing direct measurements of surface elevation and bed shear stresses and (2) a sediment-bed experiment, allowing for the measurement of morphological changes. The two experimental conditions were kept as similar as possible. In the rigid-bed experiment, the variation of the surface elevation and bed shear stress at measured sections were recorded. In addition, synchronized flow visualizations were also performed, using a digital video recorder. In the sediment-bed experiment, the bed profile was exposed to four successive solitary waves and was measured using a point gauge. The above-mentioned experimental data will be used to validate the present numerical model.

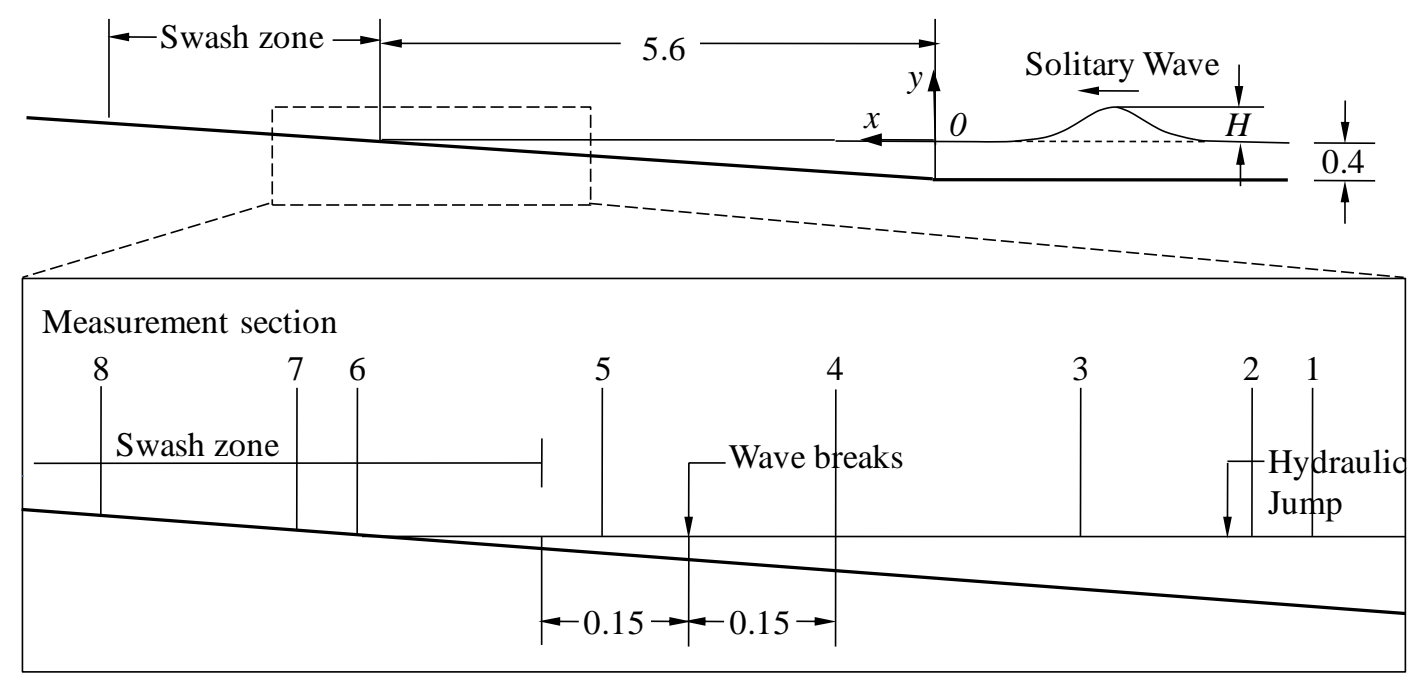

Figure 1 Experimental sketch of Sumer et al. [16]: flow and sediment transport induced by a

Table 1 Measurement point location.

\begin{tabular}{cccccccccc}
\hline Section & Toe & 1 & 2 & 3 & 4 & 5 & 6 & 7 & 8 \\
\hline$x(\mathrm{~m})$ & 0 & 4.63 & 4.69 & 4.87 & 5.11 & 5.35 & 5.59 & 5.65 & 5.85 \\
$h(t=0)(\mathrm{m})$ & 0.40 & 0.07 & 0.07 & 0.05 & 0.04 & 0.02 & 0.00 & 0.00 & 0.00 \\
\hline
\end{tabular}

\subsection{Model setup}


241 domain (i.e., in the $x$ direction) is $16 \mathrm{~m}$, from the inlet boundary at $x=-7 \mathrm{~m}$ to the outlet boundary 242 at $x=9 \mathrm{~m}$. The length between the inlet of wave generation to the toe of the slope is $7 \mathrm{~m}$, which is 243 almost a full effective wave length. This length enables initial solitary wave propagation while 244 also maintaining reasonable computational costs. Also, the outlet boundary is selected at a 245 position away from the highest point of wave runup to avoid any influence of the outlet boundary. 246 Fig. 2 shows the computational mesh used for the forthcoming numerical modeling. Body-fitted 247 quadrilateral grids were used and oriented parallel to the bottom bed. Pawel et al. [42] pointed out 248 that this type of mesh improves the accuracy of the simulation of solitary wave runup on a slope. 249 The aspect ratio of the cells in the upper part of the computational domain was kept as 2 (i.e. cell 250 length / cell height $=2$ ), which is within the range of $1 \sim 3$ proposed by Jacobsen et al. [31]. The 251 total number of cells comprising the computational domain utilized is 18,000 . We used three 252 layers of cells with height of $O\left(d_{50}\right)$ near the bed, and the height of this refined area was $3.5 d_{50}$. 253 The mesh height in the water body was extended to $7 \mathrm{~mm}$ to guarantee at least ten cells per wave 254 height $(=71 \mathrm{~mm})$. It is emphasized that considerable effort has been put into optimizing the computational mesh for convergence while at the same time keeping the computational time affordable. Regarding the influence of grid size on the computational results, see the Appendix A.

In this validation, to be exactly consistent with the experiment, two kinds of numerical simulations were carried out: (1) rigid-bed simulations to obtain the flow features; (2) sediment (mobile)-bed simulations to obtain morphological change. In the rigid bed simulation, the bottom of the computational domain was kept rigid by turning off the morphological model, whereas, in the mobile-bed simulation, the morphological model was turned on, and therefore the bed was continuously updated.

The boundary conditions of the computational domain are as follows: The top boundary (i.e. the top of the domain, not the free surface) will be modeled as a frictionless lid meaning that vertical velocities were set to zero, and horizontal velocities and scalar hydrodynamic quantities have zero vertical gradient; At the friction wall boundary (i.e. at the bottom), following Larsen et al. [6], a generalized wall function is utilized to determine the friction velocity. As the sediment transport process will be modeled, a hydraulically rough-wall will be assumed, and the Nikuradse's equivalent sand roughness of the bed was taken as $k_{s}=2.5 d_{50}$; At the inlet (right hand) boundary, a prescribing velocity method was used to generate a solitary wave; For the left-hand boundary a slip boundary condition was specified, though it is emphasized that this is a sufficient distance away such that the water does not reach this boundary. To maintain the stability and accuracy of the computation, the Courant number is set as 0.05 , which is far less than 1 . This value is referenced to the result proposed by Larsen et al. [43] who noted that a small Courant number is crucial for limiting the growth of spurious velocities in wave simulations. 
use of morphological rates averaged over any larger time scales or morphological acceleration. The reason for this choice is the rapid change in the development of the bed during wave induced morphology requires close coupling between the hydrodynamics and the bed evolution. To reduce the simulation time, we used parallel computation with domain decomposition on five processors. To be consistent with the time duration of the experiment, the physical time of simulation was set as $20 \mathrm{~s}$. For the mobile-bed simulation, it required approximately 3 days of CPU time. For the same computational mesh and using the same computational power, the rigid-bed simulation for $20 \mathrm{~s}$ of physical time required approximately 1 day. All computations were done on the clusters supported by High Performance Computing (HPC) Competence Center at the Technical University of Denmark.

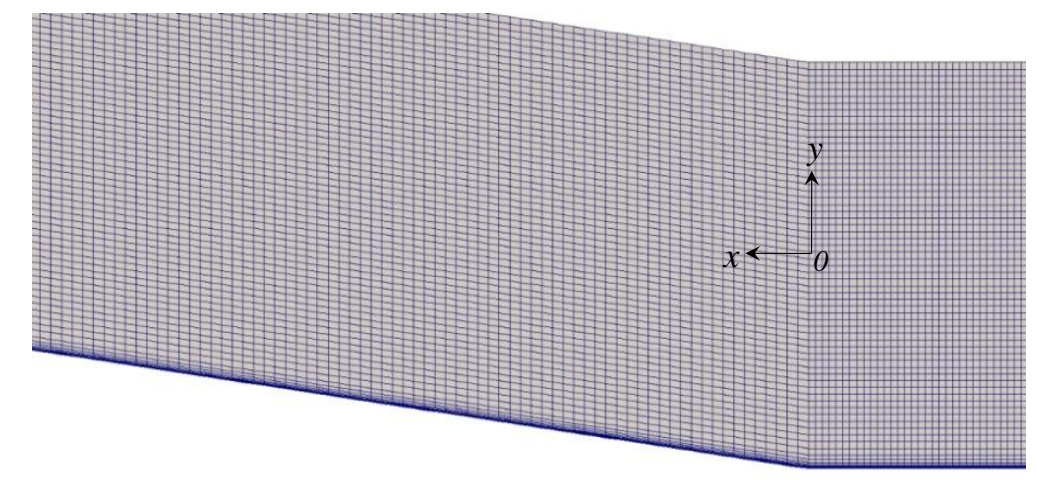

Figure 2 Example of the computational mesh used in the present simulation.

\subsection{Rigid-bed simulation}

The numerical results of the complete sequence of the breaking solitary wave are illustrated in Fig. 3, in which the small numbers denote different stages of the process. To clearly show the variation of the wave surface, the figure is scaled such that the vertical coordinate is enlarged relative to the horizontal coordinate. It is shown that the numerical model qualitatively reproduces the sequences observed in the experiment. Fig. 3 (a) shows the stage of wave shoaling and breaking, during which the incoming wave from offshore side transforms and deforms on the slope due to water becoming shallow, followed by wave breaking. Subsequently, the breaking wave runs up on the slope due to the excessive kinetic energy, as shown in Fig. 3 (b). After the wave runs up to the highest point, it stars to run down, as shown in Fig. 3 (c). During the rundown stage, the flow is strong enough to move the shoreline in the seaward direction, and a hydraulic jump occurs near the shoreline. Fig. 3 (d) shows that the shoreline moves back to its original position creating trailing waves. We also conducted a quantitative validation of wave profile with the experimental results from Chang et al. [44], which can be seen in Appendix B. 


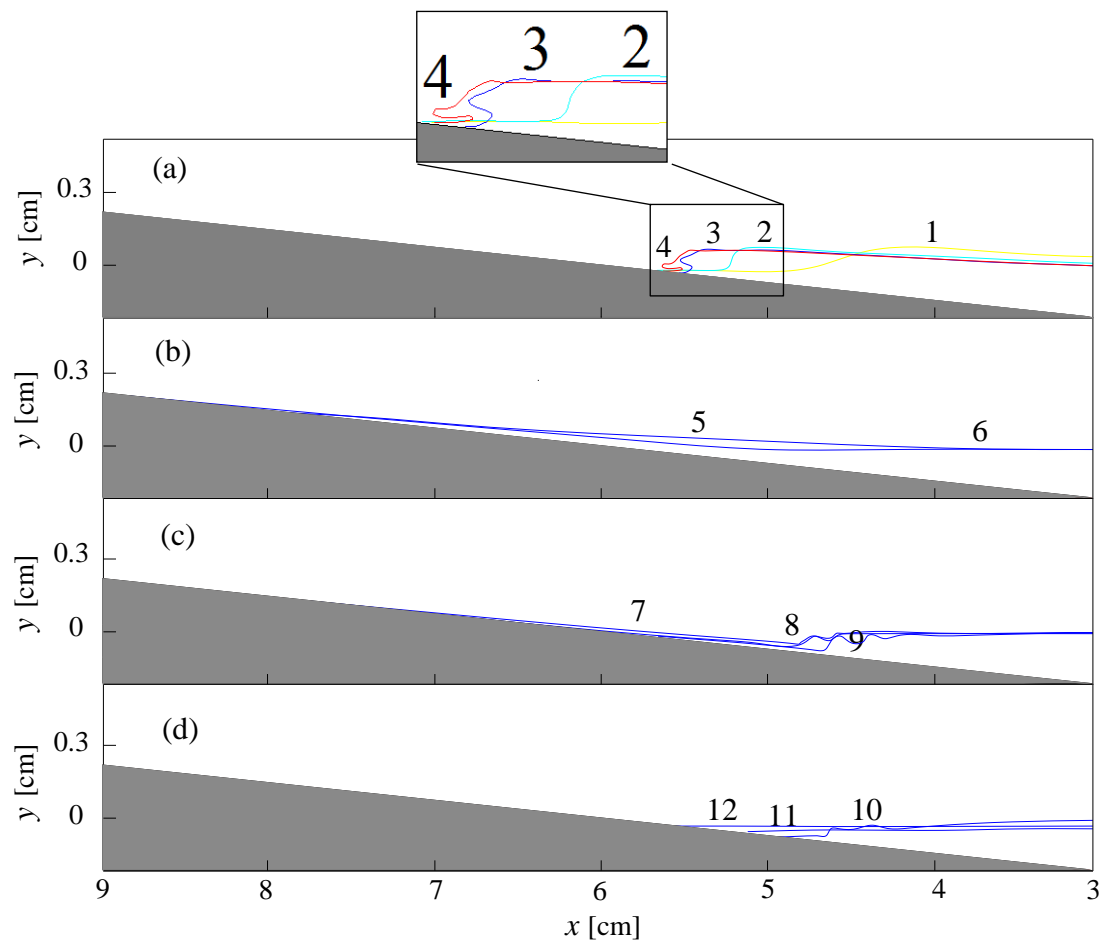

Figure 3 Breaking solitary wave sequence simulated by the present numerical model: (a) shoaling and wave breaking; (b) runup; (c) rundown and hydraulic jump; (d) trailing wave. Note that this figure is scaled to be clearly seen.

Quantitative comparisons of the water surface elevation $\eta$ and mean bed shear stress $\tau_{b}$ between computed and measured data at different sections are given in Figs. 4 and 5, respectively, in which the blue solid line and black dotted line represent the computed and measured results, respectively. Overall, the numerical modeling results fit well with the experimental results, particularly during the wave runup stage. However, discrepancies can be found during the rundown stage, e.g., for sections 1 and 2 (near the hydraulic jump position), deviations exist during the rundown stage at approximate $t=7 \mathrm{~s} \sim 12 \mathrm{~s}$. Specifically, the computed $\eta$ is larger than was measured (Fig. 4 (b)) and the computed $\tau_{b}$ is correspondingly smaller (Fig. 5 (b)). This deviation is probably attributed to the existence of the hydraulic jump as a rather complicated phenomenon that is difficult to be accurately simulated [45]. Additionally, for section 8 in the swash zone, $\eta$ is generally overestimated (Fig. 4 (e)) and $\tau_{b}$ is correspondingly underestimated (Fig. 5 (e)). The reason is that the water depth within the swash zone is extremely small during the rundown, forming a thin-layer of flow, which is also difficult to accurately capture utilizing the present numerical model. A similar issue was also pointed out by Pawel et al. [42]. Nevertheless, the modeling results are deemed satisfactory, particularly considering the complexity in the physical processes e.g. involving wave shoaling, breaking, and hydraulic jump. 


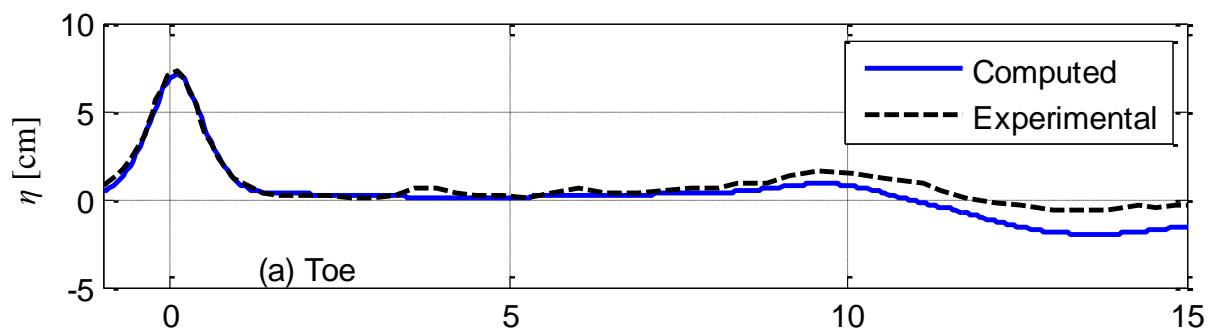

$t[\mathrm{~s}]$
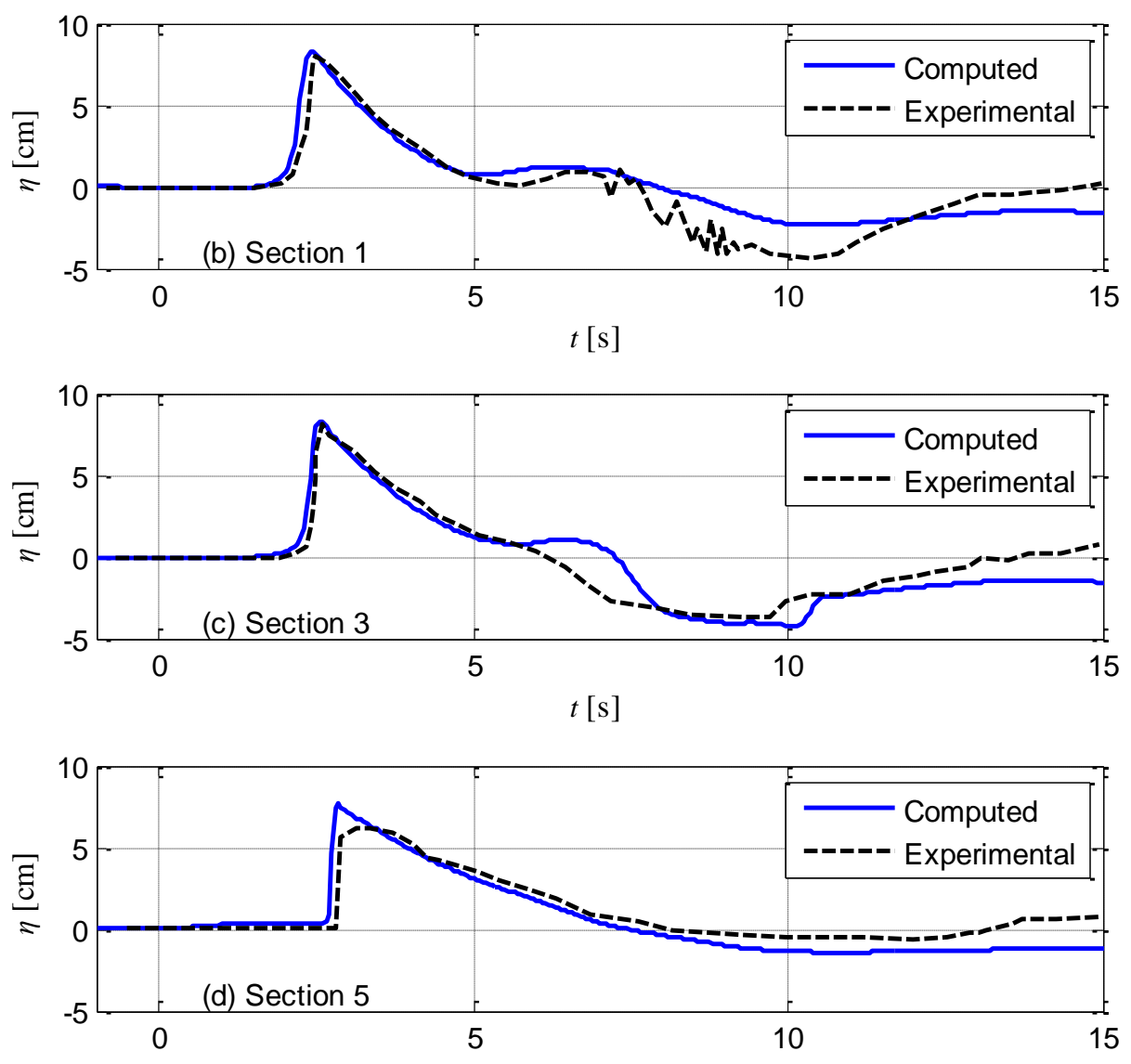

$t[\mathrm{~s}]$

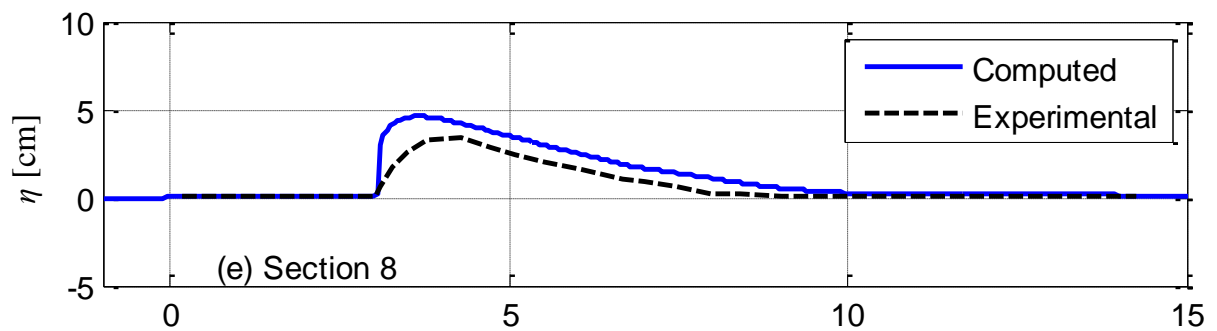

$t$ [s]

Figure 4 Water surface elevation comparison: (a) Toe; (b) Section 1; (c) Section 3; (d) Section 5;

(e) Section 8 . 

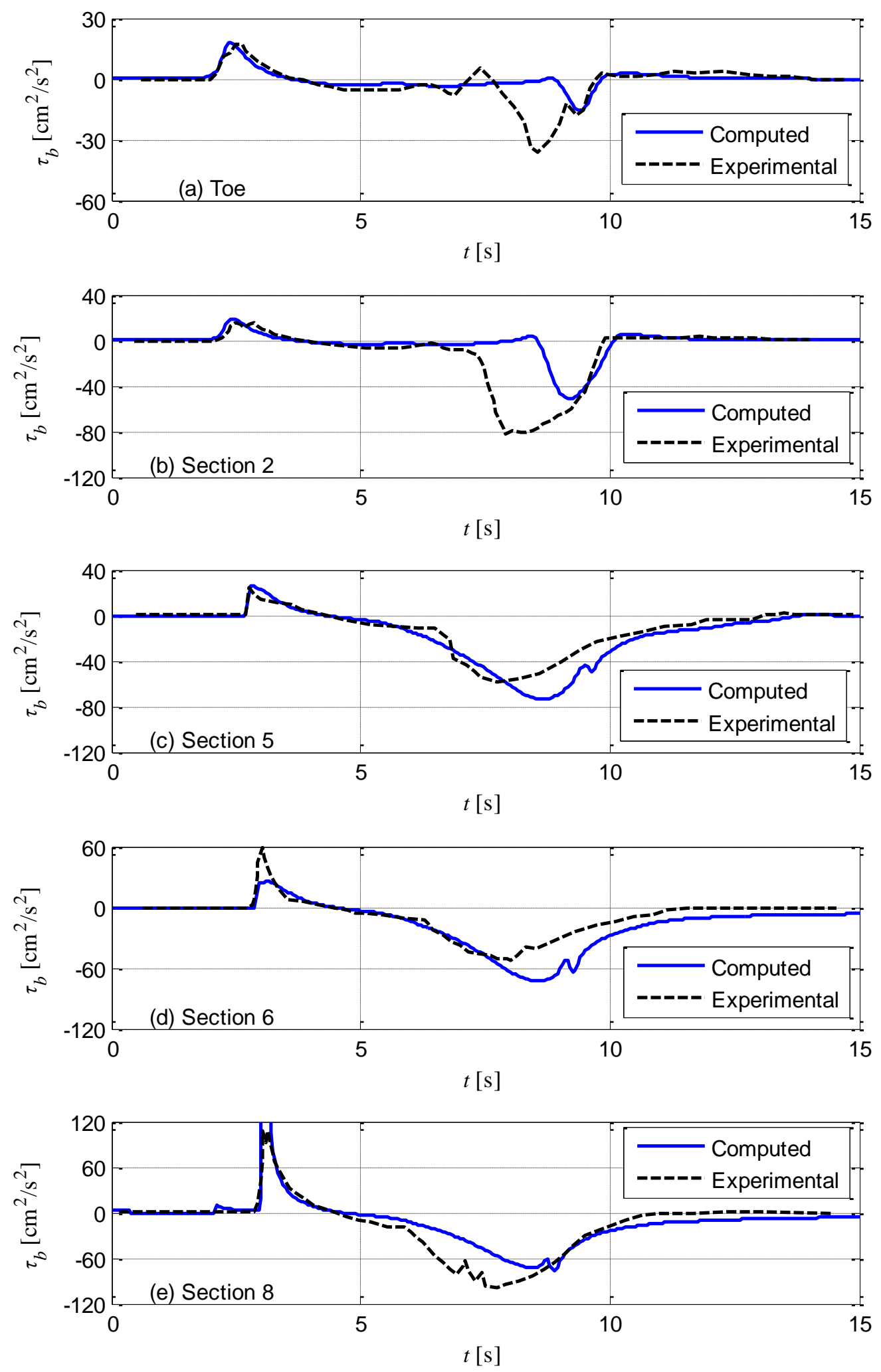

Figure 5 Bed shear stress comparison: (a) Toe; (b) Section 2; (c) Section 5; (d) Section 6; (e) Section 8 .

The mean bed shear stress is normally regarded as a key factor driving sediment motion, and 
339 thus we further analyzed the spatial variation of mean bed shear stress during the entire process of 340 wave evolution on the slope. Fig. 5 illustrates that two distinct peaks occur for both computed and 341 measured bed shear stress. The first and second peaks occurred during the wave runup and 342 rundown stages, respectively. We extracted the peak value of bed shear stress $\tau_{\max }$ at different 343 sections and these are plotted in Fig. 6. Fig. 6 (a) corresponds to the shoaling and runup stages 344 while Fig. 6 (b) corresponds to the rundown and hydraulic jump stages. Since the peak value of 345 the bed shear stress during the rundown stage is negative, for consistency, the absolute value $\left|\tau_{\max }\right|$ 346 was used, as shown in Fig. 6 (b).

$347 \quad$ Figure 6 clearly shows that the computed results generally fit well with the measured results 348 although discrepancy exits especially for the section in the swash zone as discussed above. Fig. 6 349 (a) illustrates that $\tau_{\max }$ is small $\left(O\left(10 \mathrm{~cm}^{2} / \mathrm{s}^{2}\right)\right)$ before wave breaking, while it increases 350 significantly after wave breaking during the runup stage, and $\tau_{\max }$ even reaches to $O\left(100 \mathrm{~cm}^{2} / \mathrm{s}^{2}\right)$ 351 for the section in the swash zone. Fig. 6 (b) shows that $\left|\tau_{\max }\right|$ decreases gradually during the 352 rundown stage. It should be mentioned that $\left|\tau_{\max }\right|$ measured in the hydraulic jump zone increases 353 dramatically, whereas this feature is not reproduced by the numerical model. The reason has been 354 mentioned above that the hydraulic jump is a complicated chaotic phenomenon involving e.g. air 355 entrainment, large turbulent fluctuations of velocity and energy dissipation, which is apparently 356 difficult to be accurately modeled [45]. Nevertheless, in the present work, we mainly focus on the 357 surf and swash zones where the hydrodynamics are more relevant to morphological evolution in 358 coastal regions. 


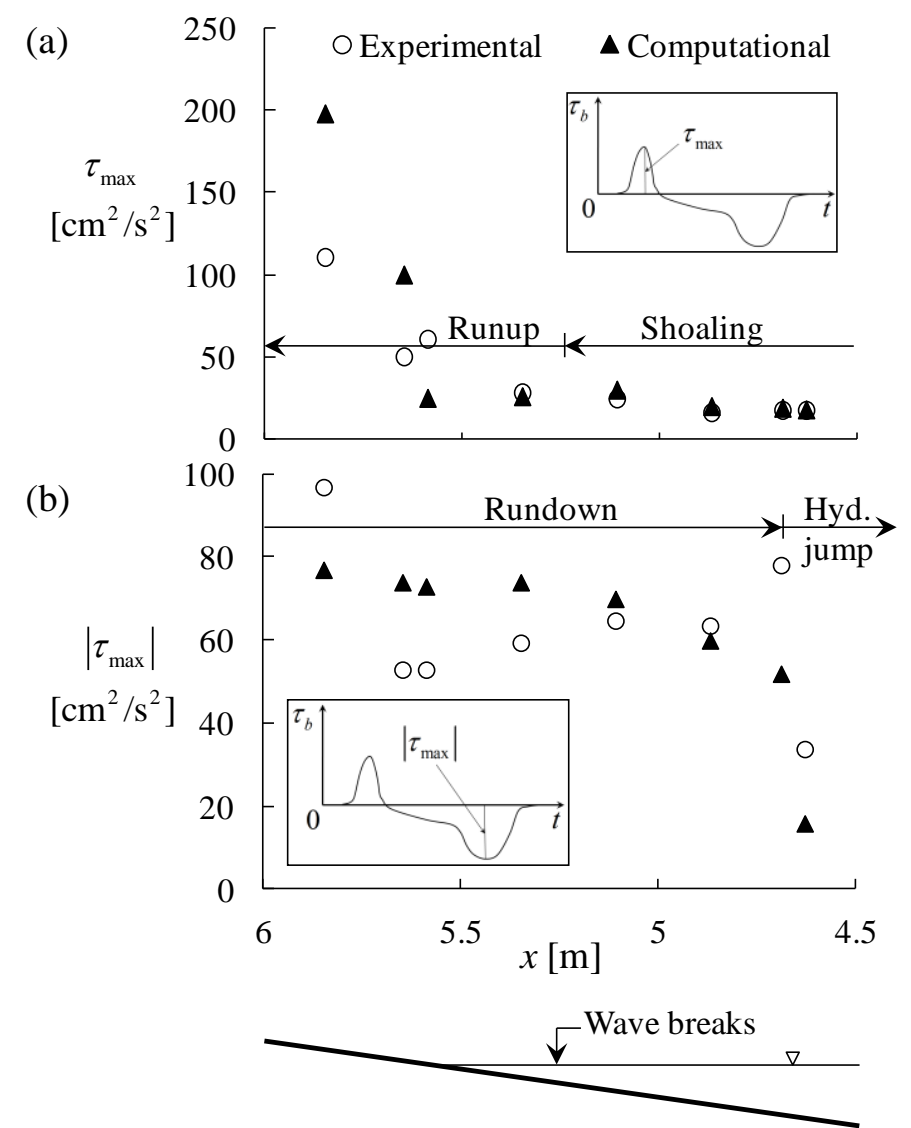

Figure 6 The $x$ variation of the peak value of the bed shear stress (a) during the shoaling and runup stages and (b) during the rundown and hydraulic jump stages.

The turbulent intensity can be reflected to some extent by the turbulent kinetic energy $(k)$ in the RANS modeling. Fig. 7 shows the variation of $k$ with time at different measured sections. It clearly shows that two peaks appear at the corresponding runup and rundown stages. In the experiment of Sumer et al. [16], the bed shear stress fluctuation was measured. The bed shear stress fluctuation and turbulent kinetic energy cannot be compared directly. However, they both show the turbulence behavior in the boundary layer. Thus, from the perspective of general tendency, similar behavior between the two parameters is expected. The peak values of turbulent kinetic energy $k_{\max }$ at both runup and rundown stages were extracted and plotted in Figs. 8 (a) and (b), respectively. From Fig. 8 (a), it can be seen that $k_{\max }$ is small before wave breaking while $k_{\max }$ increases significantly after wave breaking, especially for the measured point at the swash zone $\left(k_{\max } \approx O\left(1000 \mathrm{~cm}^{2} / \mathrm{s}^{2}\right)\right)$. This numerical result is consistent with the experimental result (see Figs. 5 and 9 of [16]). Fig. 8 (b) illustrates that the variation of $k_{\max }$ with $x$ during the rundown stage is not obvious, and the value of $k_{\max }$ is almost constant, while $k_{\max }$ decreases dramatically at the hydraulic jump region. 

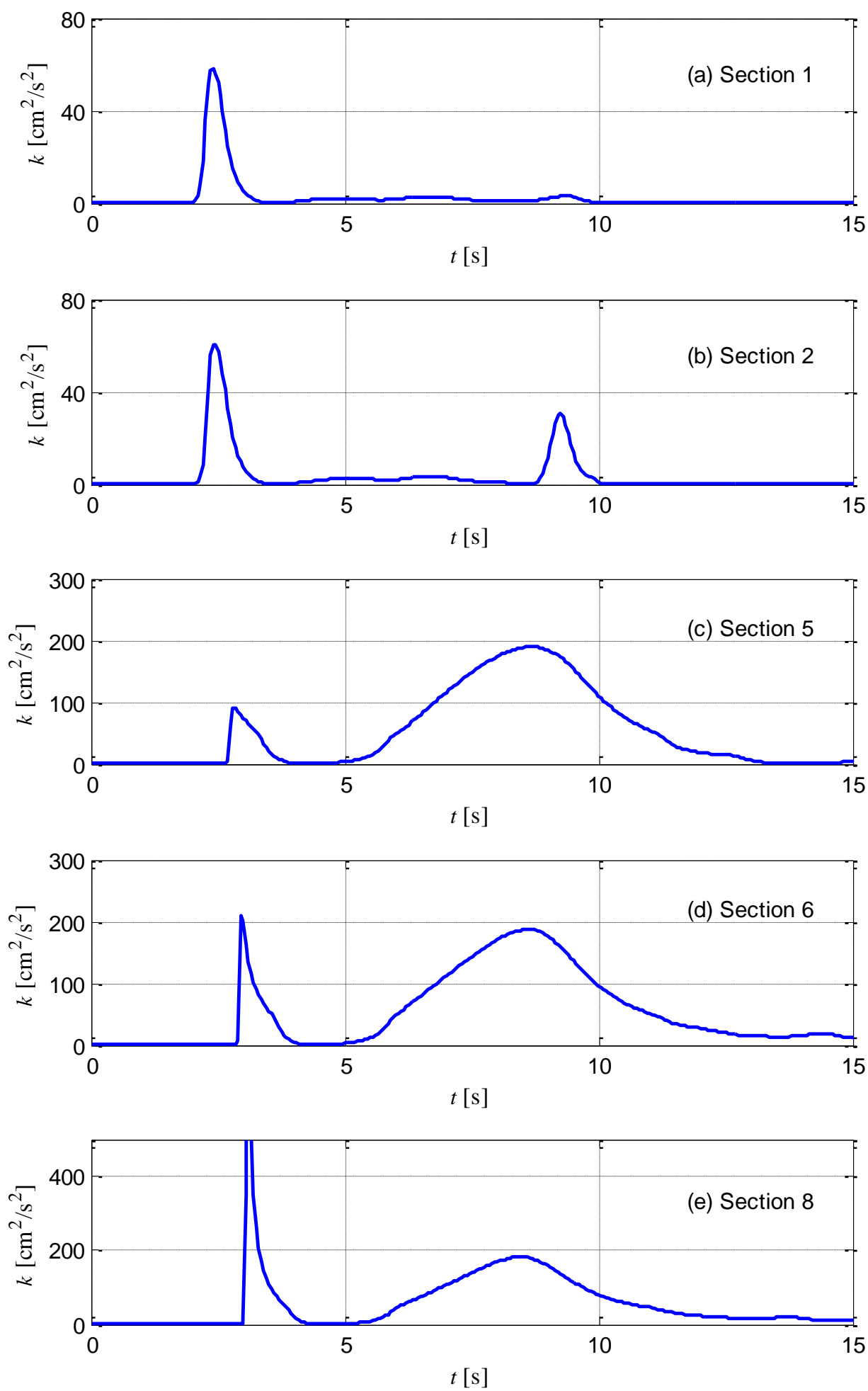

Figure 7 Time variations of the turbulent kinetic energy at different sections computed by the 381 present numerical model: (a) Section 1; (b) Section 2; (c) Section 5; (d) Section 6; (e) Section 8. 


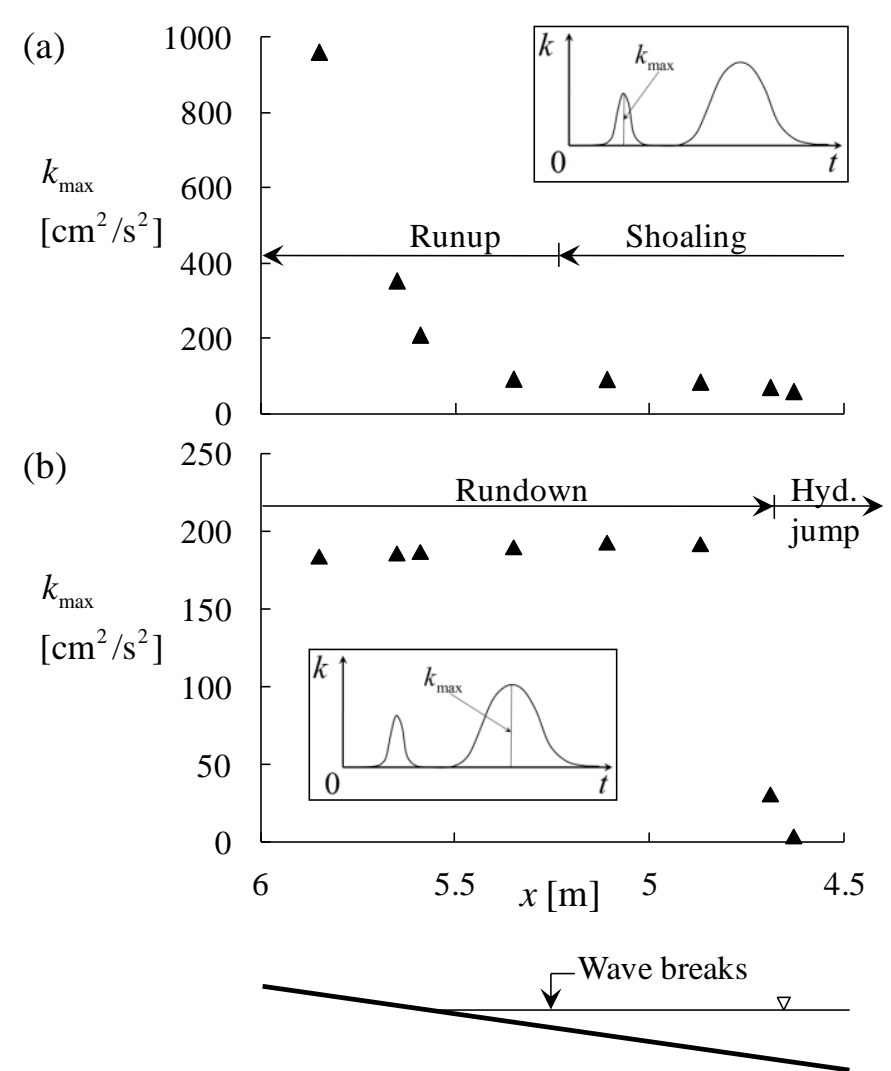

383

384

Figure 8 The $x$ variation of the peak value of turbulent kinetic energy computed by the present numerical model (a) during the shoaling and runup stages and (b) during the rundown and hydraulic jump stages.

\subsection{Sediment-bed simulation}

The sequence of morphology computed by the present fully-coupled numerical model during the initial solitary wave rundown stage ( $t \geq 8 \mathrm{~s}$ ) is given in Fig. 9, in which the red solid line and blue dashed line represent the bed profile and water surface, respectively. The vertical axes are exaggerated to highlight the bed morphological change. It shows that the bed change, involving erosion and deposition, mainly occurs during the rundown stage, especially for the swash zone where an extremely thin water layer is formed. According to the preceding description of the rigid-bed results, the bed shear stress and turbulent kinetic energy during the rundown stage increase significantly, especially within the swash zone, which directly induces increased sediment transport. The transported sediment from the swash zone deposits at the hydraulic jump region forming the beginning of a single breaker bar. Generally, the present model is capable of reasonably reproducing the erosion and deposition process observed in the experiment.

Figure 10 shows the spatial variation of bottom velocity magnitude at the corresponding moment of Fig. 9. The velocity magnitude is normalized and defined as $U_{b}=\sqrt{U_{x}{ }^{2}+U_{y}{ }^{2}} / \sqrt{g h}$. Combing with the results in Fig. 9, it can be seen that the velocity variation is closely related to 

rundown stage, which induces the sediment transport at the corresponding locations and the resultant morphological change.

406

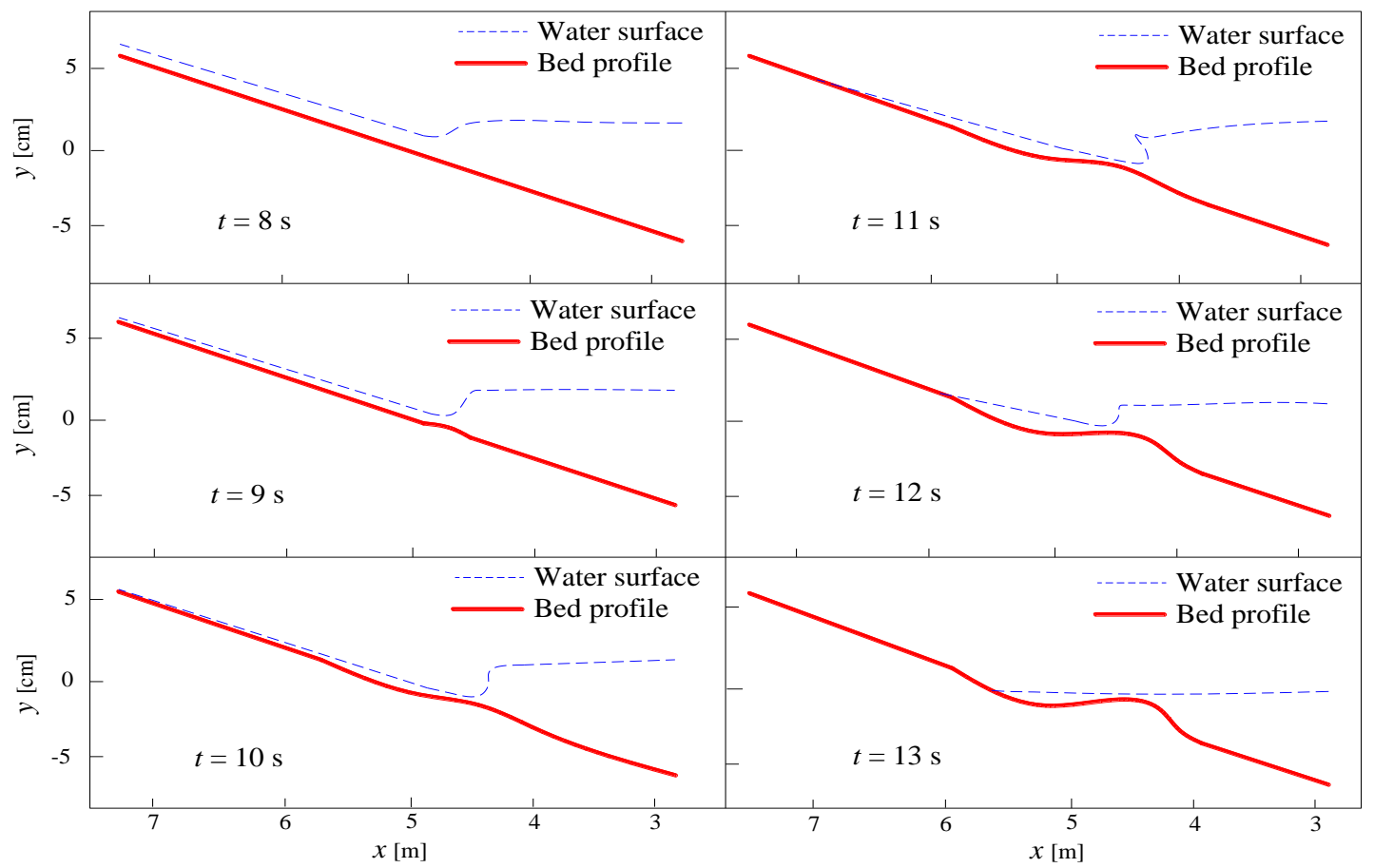

Figure 9 Sequence of simulated bed profile (red solid line) and water surface (blue dashed line) 

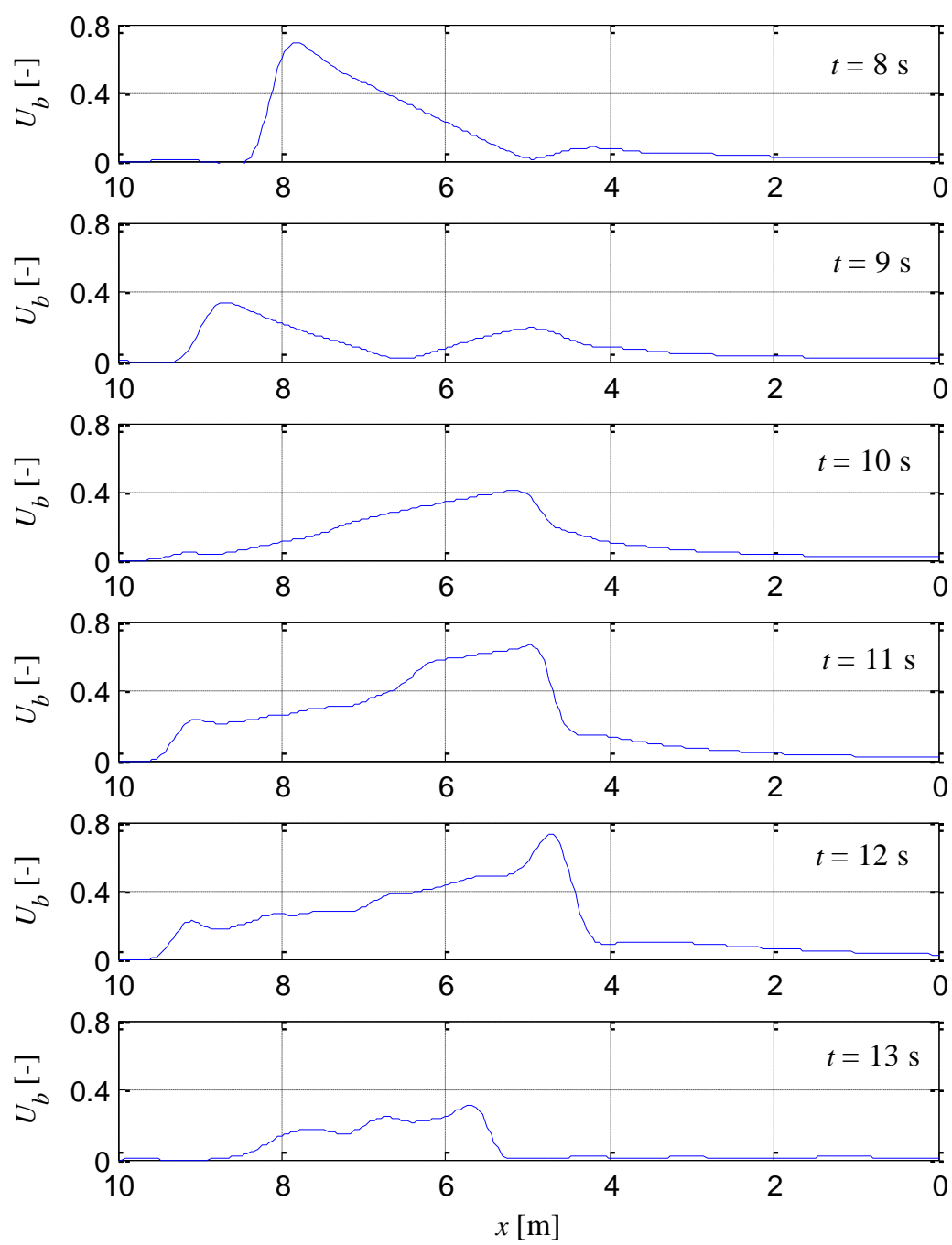

Fig. 10 Spatial variation of bottom velocity magnitude at the corresponding moment in Fig. 9.

In the present work, the bed profiles after more than one solitary wave were also computed and compared with the experimental data, as shown in Fig. 11. The dots represent the experimental data after four successive waves, and different colored lines represent the computed

417 bed profiles after each successive wave. Although the experimental data in Fig. 11 is limited (only 4188 points), several insights from the comparison of the bed profiles can be obtained: (1) the general erosion and deposition pattern computed after four waves fits reasonably with the measured result, especially considering the complexity of the process. More specifically, both results show that erosion occurs on the onshore side of the wave breaking $(x \approx 5 \sim 7 \mathrm{~m})$, whereas deposition occurs on the offshore side ( $x \approx 4 \sim 5 \mathrm{~m}$ ); (2) the deposition is well simulated, especially for the measured point at location $x=4.9 \mathrm{~m}$, where the computed deposition height agrees fairly well with the measured data (see the enlarged block-figure inserted in Fig. 11); (3) the computed erosion is generally smaller than was measured. The reason for this discrepancy is probably two-fold. First, the aforementioned rigid-bed results demonstrate that the surface elevation in the 
swash zone is overestimated (see Fig. 4 (e)) and the bed shear stress is underestimated (see Fig. 5 (e)), thus the computed sediment transport and erosion is correspondingly less than the experimental result. Second, Sumer et al. [16] found that the pore water pressure measured in the experiment has a great impact on the sediment transport during the rundown stage. The sediment at the surface of the bed experiences upward directed pressure gradient force, and the magnitude of this force can reach values as high as approximately $30 \%$ of the submerged weight of the sediment. Sui et al. $[46,47]$ also found that the seepage force can make influence on the adjacent of soil particles which may affect the erosion of the seabed. This factor of pore water pressure is not taken into account in the present numerical model. However, in general, the agreement is considered satisfactory, and the results obtained from the present numerical model can be considered promising, particularly considering the complexity of the coupled hydrodynamic, sediment transport, and morphological processes involved.

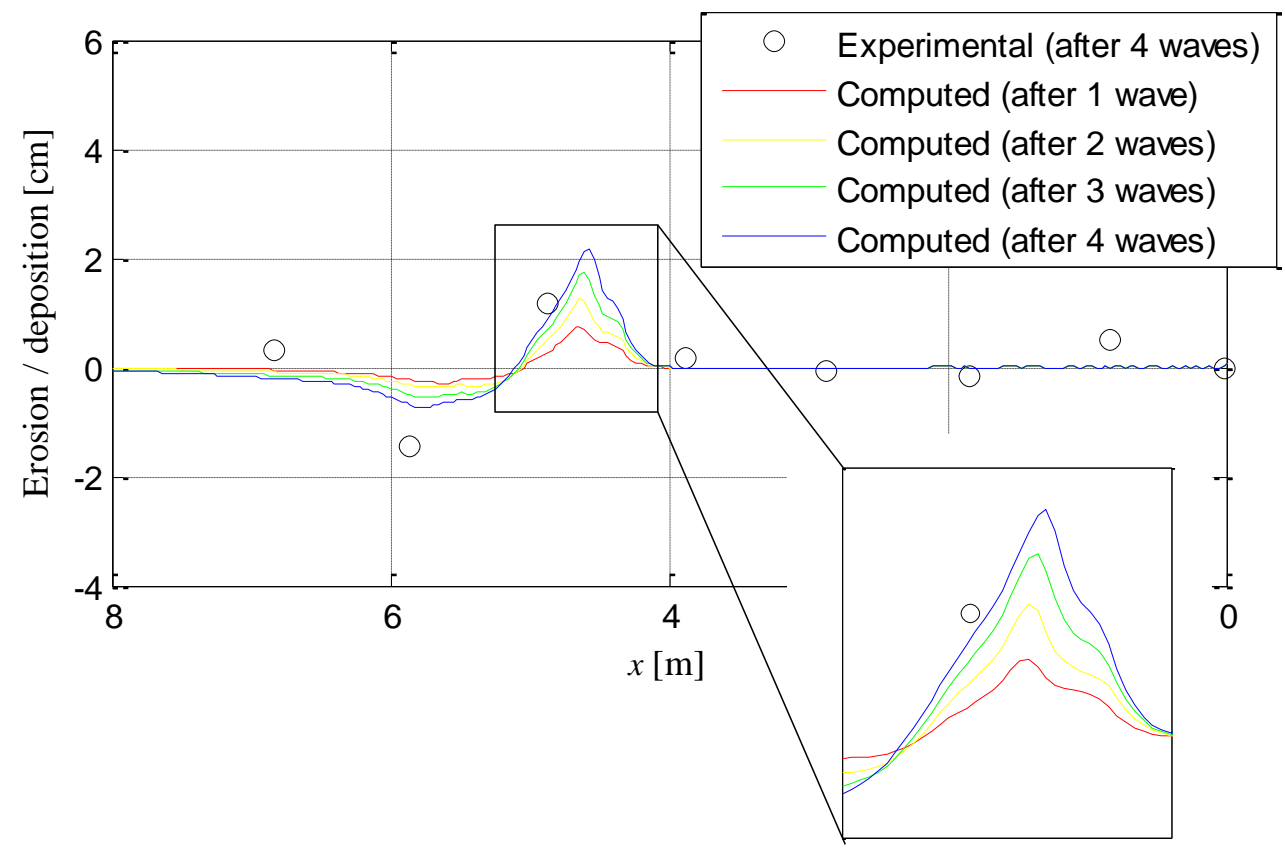

Figure 11 Comparisons between computed (lines) and experimental (dots) bed profiles after

\section{Summary and conclusions}

A fully-coupled hydrodynamic and morphologic numerical model based on the open-source CFD package OpenFOAM is presented (based on Jacobsen et al. [31]) and utilized to simulate flow and morphology induced by a solitary wave on a sloping beach. The hydrodynamic model is

448 based on Reynolds-averaged Navier-Stokes (RANS) equations together with $k$ - $\omega$ turbulence closure and volume of fluid (VOF) method for capturing the free surface. Waves are generated 
using the waves2Foam package [26]. The sediment transport consists of both bed load and suspended load descriptions, and the latter is based on a turbulent diffusion equation. The morphological model is based on the sediment continuity (Exner) equation, accounting for sand-slide adjustments.

The present numerical model is validated and tested against a laboratory experiment of Sumer et al. [16] who performed the flow and morphology induced by a solitary wave, including both rigid-bed and sediment-bed cases. The rigid-bed validation illustrates that the present numerical model can well reproduce the characteristic sequences observed in the experiment, including wave shoaling, breaking, runup, rundown, hydraulic jump and trailing wave. The quantitative comparison of hydrodynamic results, including water surface elevations, bed shear stresses and turbulent kinetic energy, illustrate satisfactory agreements between computed and measured data, especially during the wave runup stage. However, discrepancies exist during the rundown stage, especially for the section in the swash zone where the water layer is extremely thin and thus difficult to be accurately captured.

Sediment-bed modeling results demonstrate that the bed change, involving erosion and deposition, mainly occurs during the rundown stage where the bed shear stress and turbulent kinetic energy increase significantly. The computed tendency of bed profile morphology fits well with the measured result, demonstrating the general pattern of offshore deposition and onshore erosion. The deposition height is fairly well simulated, while the erosion depth is generally underestimated. This is likely due to the underestimation of the bed shear stress in the swash zone as well as the model employed not accounting for pore water pressures.

Overall, the results obtained from the present numerical model are promising, particularly considering the complexity of the coupled hydrodynamic and sediment transport process involved. Additionally, the present work can be used as a validation study for planned future work on numerical simulation of wave-induced local scour around coastal structures.

\section{Acknowledgements}

This research was financially supported by the National Natural Science Foundation of China (Grant No. 51578062). The first author would like to thank Bjarke Eltard Larsen for his helpful discussion and suggestions. The computational resources provided by the High Performance Computing (HPC) Competence Center at the Technical University of Denmark are gratefully acknowledged. The third author additionally acknowledges financial support from the Independent Research Fund Denmark project: SWASH: Simulating Wave Surf-zone Hydrodynamics and Sea Bed Morphology, Grant no. 8022-00137B. 


\section{Appendix A: Grid convergence}

485

486

487

488

489

490

491

492

493

494

495

496

497

498

To investigate the influence of grid size on the computational results, we tested two different rigid-bed meshes as shown in Fig. A. 12, in which the fine mesh is refined with cells twice as small compared to the coarse mesh. The coarse mesh is the present mesh used in this work. It clearly shows that the computed wave surface elevations by the two meshes are quite similar, especially in the runup region (almost overlapped). Figure A. 13 shows the time variations of the velocity magnitude at different sections, in which two computed results using different mesh resolutions are also included. The velocity is selected at the point nearest the bed, and the magnitude is normalized and defined as $U_{b}=\sqrt{U_{x}^{2}+U_{y}{ }^{2}} / \sqrt{g h}$. It clearly shows that two peaks appear during the wave runup and rundown stages, and both the results of the coarse and fine meshes nearly overlap. As a check of convergence, it can be noted that further refinements in the mesh yield the same results. In addition, the required CPU time for the finer computational meshes is approximately 8 days, which is more than twice time compared to coarse meshes (3 days). Thus, to balance the computational precision and speed, the coarse mesh has been adopted. 

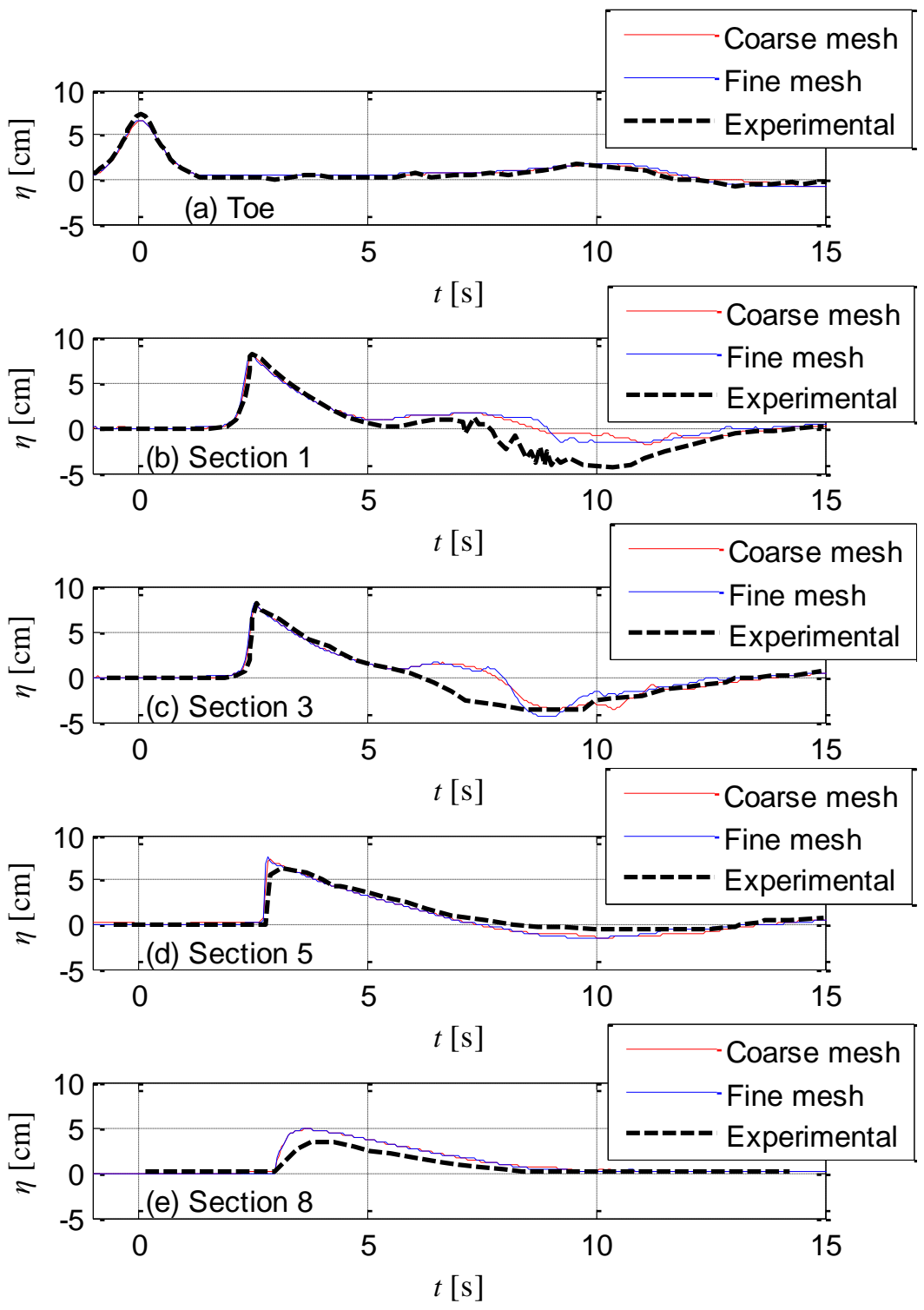

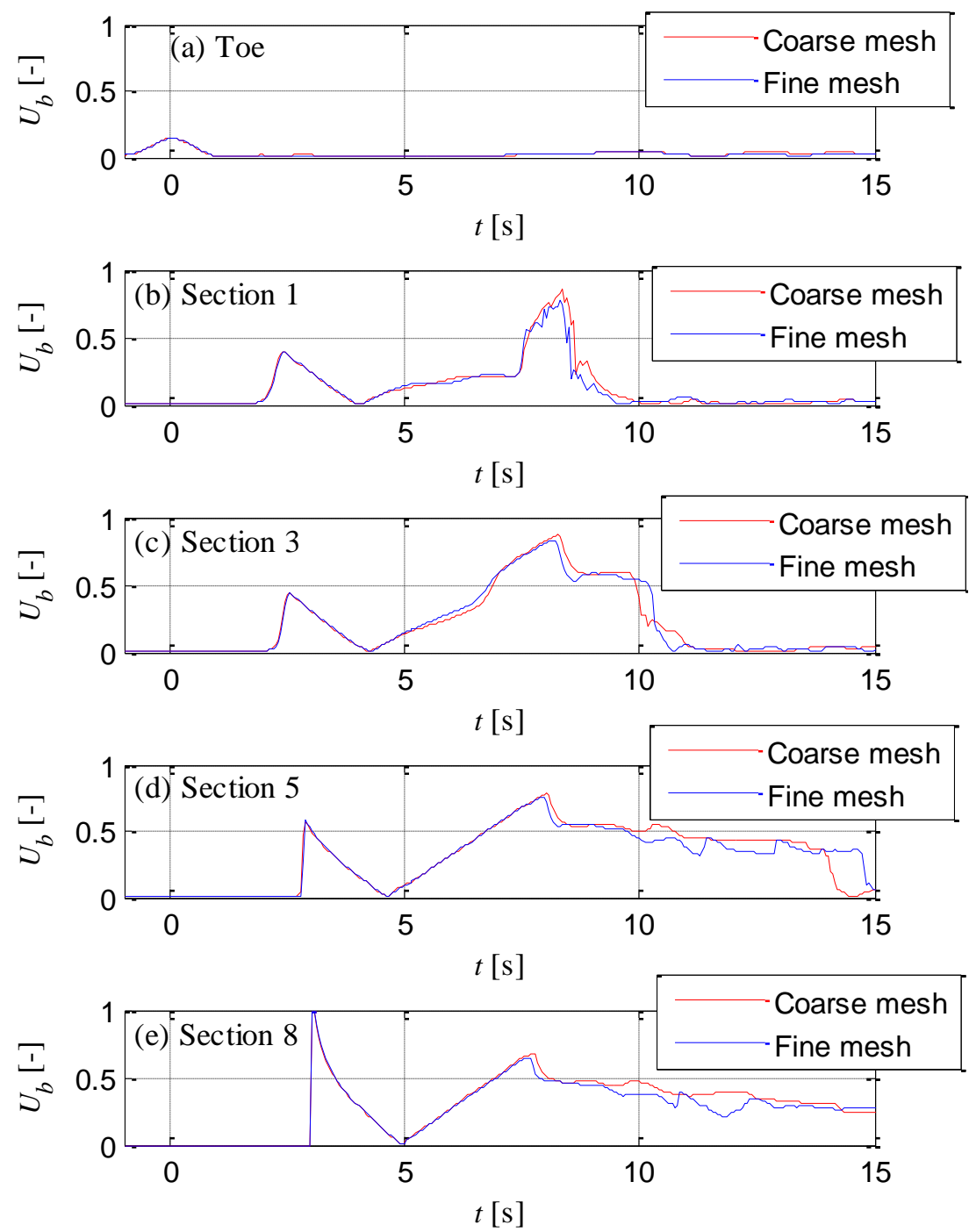

Figure A.13 Time variations of the computed velocity magnitude at different sections computed by the present numerical model using different meshes: (a) Toe; (b) Section 1; (c) Section 3; (d) Section 5; (e) Section 8.

\section{Appendix B: Validation against measured surface elevations}

As additional validation, Fig. B. 14 presents further comparisons between computed and experimental wave surface elevations, in which the experimental results are from Chang et al. [44]. In the experiment, the relative wave height $H / h$ is 0.235 , the still water depth $h$ is $1.75 \mathrm{~m}$ and the beach slope is $1 / 20$. It can be seen that the numerical results agree well with the experimental results, which demonstrates that the present model is indeed capable of accurately simulating the propagation and transformation of solitary waves on a sloping beach. 

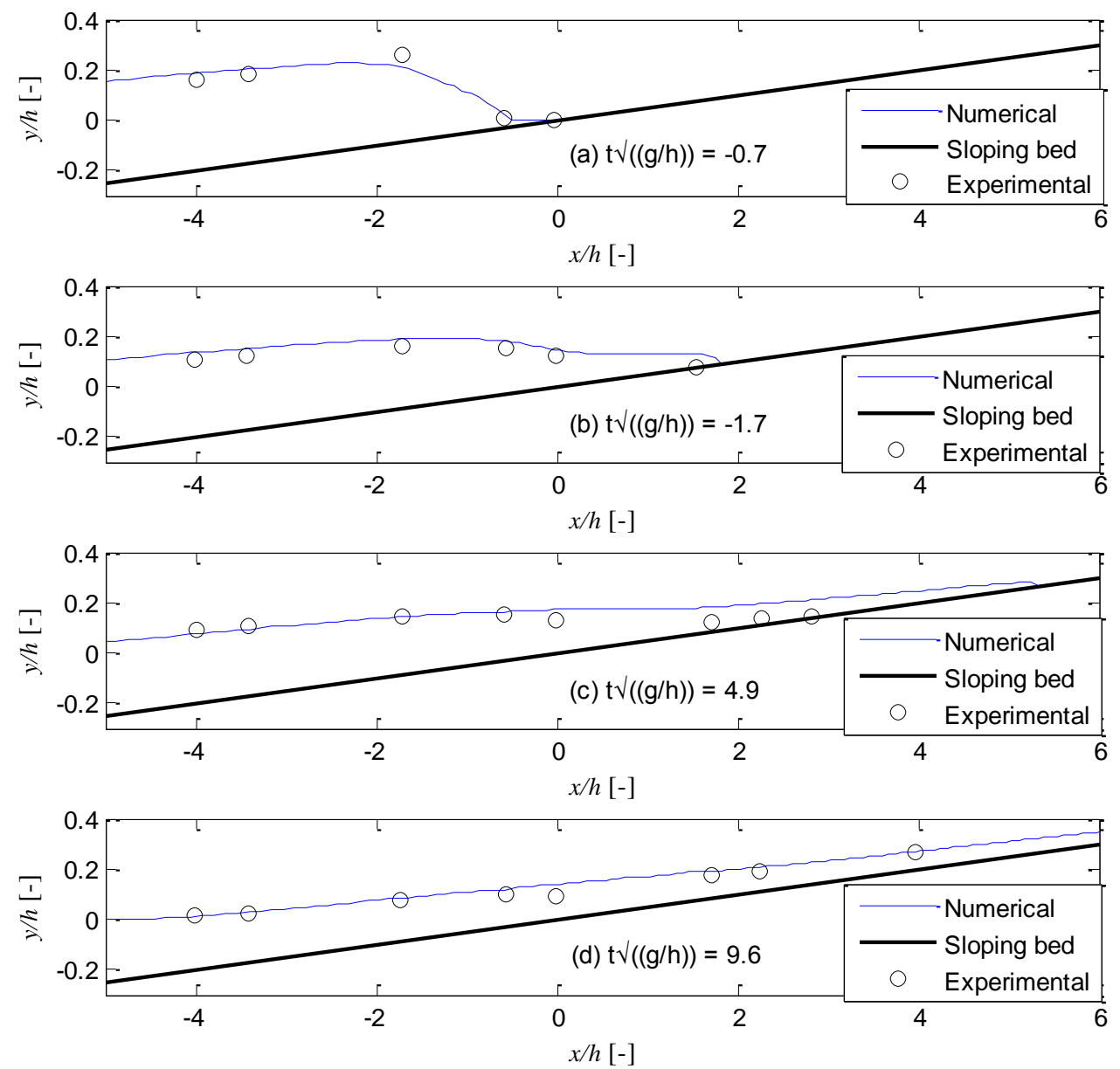

515 Figure B. 14 Comparison of wave surface in spatial between numerical and experimental results.

\section{References}

518 [1] J. Fredsøe, R. Deigaard, Mechanics of Coastal Sediment Transport, World Scientific, 1992.

519 [2] Y. L. Young, H. Xiao, T. Maddux, Hydro- and morpho-dynamic modeling of breaking solitary waves over a fine sand beach. part I: Experimental study, Marine Geology 269 (2010) 107-118.

[3] S. Tonkin, H. Yeh, F. Kato, S. Sato, Tsunami scour around a cylinder, Journal of Fluid Mechanics 496 (2003) 165-192.

[4] A. W. Nielsen, B. M. Sumer, S. S. Ebbe, J. Fredsøe, Experimental study on the scour around a monopile in breaking waves, Journal of Waterway, Port, Coastal, and Ocean Engineering 138 (2012) 501-506.

[5] J. Chen, C. Jiang, W. Yang, G. Xiao, Laboratory study on protection of tsunami-induced scour by offshore breakwaters, Natural Hazards 81 (2016) 1229-1247. 
foundations, Coastal Engineering 129 (2017) 36-49.

[7] J. M. Alsina, S. Falchetti, T. E. Baldock, Measurements and modelling of the advection of suspended sediment in the swash zone by solitary waves, Coastal Engineering 56 (2009) 621-631.

[8] S. C. Hsiao, T. C. Lin, Tsunami-like solitary waves impinging and overtopping an impermeable seawall: experiment and RANS modeling, Coastal Engineering 57 (2010) 1-18.

[9] C. Jiang, J. Chen, Y. Yao, J. Liu, Y. Deng, Study on threshold motion of sediment and bedload transport by tsunami waves, Ocean Engineering 100 (2015) 97-106.

[10] S. C. Hsiao, T. W. Hsu, T. C. Lin, Y. H. Chang, On the evolution and run-up of breaking solitary waves on a mild sloping beach, Coastal Engineering 55 (2008) 975-988.

[11] W. Mo, A. Jensen, L. F. Liu, Plunging solitary wave and its interaction with a slender cylinder on a

[12] C. Lin, P. H. Yeh, M. J. Kao, M. H. Yu, S. C. Hsieh, S. C. Chang, Velocity fields in near-bottom and boundary layer flows in prebreaking zone of a solitary wave propagating over a 1:10 slope, Journal of Waterway, Port, Coastal, and Ocean Engineering 141 (2015) 04014038.

[13] H. J. Hafsteinsson, F. M. Evers, W. H. Hager, Solitary wave run-up: wave breaking and bore propagation, Journal of Hydraulic Research 55 (2017) 787-798.

[14] N. Kobayashi, A. R. Lawrence, Cross-shore sediment transport under breaking solitary waves, Journal of Geophysical Research Oceans 109 (2004) 325-347.

[15] R. Briganti, A. Torres-Freyermuth, T. E. Baldock, M. Brocchini, N. Dodd, T. J. Hsu, Advances in numerical modelling of swash zone dynamics, Coastal Engineering 115 (2016) 26-41.

[16] B. M. Sumer, M. B. Sen, I. Karagali, B. Ceren, J. Fredsøe, M. Sottile, Flow and sediment transport induced by a plunging solitary wave, Journal of Geophysical Research Oceans 116 (2011) C01008.

[17] M. Qi, Y. Kuai, J. Li, Numerical simulation of water waves generated by seabed movement, Applied Ocean Research 65 (2017) 302-314.

[18] Y. Kuai, M. Qi, J. Li, Numerical study on the propagation of solitary waves in the near-shore, Ocean Engineering 165 (2018) 155-163.

[19] N. G. Jacobsen, J. Fredsøe, Formation and development of a breaker bar under regular waves. part 2: sediment transport and morphology, Coastal Engineering 88 (2014) 55-68.

[20] G. Lupieri, G. Contento, Numerical simulations of 2-D steady and unsteady breaking waves, Ocean Engineering 106 (2015) 298-316. 

spilling and plunging breakers in the surf zone, Coastal Engineering 114 (2016) 177-193.

[22] P. Higuera, J. L Lara, I. J. Losada, Simulating coastal engineering processes with OpenFOAM®, Coastal Engineering 71 (2013) 119-134.

[23] L. F. Chen, J. Zang, A. J. Hillis, G. C. J. Morgan, A. R. Plummer, Numerical investigation of wave-structure interaction using OpenFOAM, Ocean Engineering 88 (2014) 91-109.

[24] B. Seiffert, M. Hayatdavoodi, R. C. Ertekin, Experiments and computations of solitary-wave forces on a coastal-bridge deck. part I: flat plate, Coastal Engineering 88 (2014) 194-209.

[25] Z. Z. Hu, D. Greaves, A. Raby, Numerical wave tank study of extreme waves and wave-structure interaction using OpenFOAM $®$, Ocean Engineering 126 (2016) 329-342.

[26] N. G. Jacobsen, D. R. Fuhrman, J. Fredsøe, A wave generation toolbox for the open-source CFD library: OpenFoam®, International Journal for Numerical Methods in Fluids 70 (2012) 1073-1088.

[27] N. G. Jacobsen, waves2Foam Manual, Deltares, The Netherlands, 2017.

[28] H. Xiao, Y. L. Young, J. H. Prévost, Hydro- and morpho-dynamic modeling of breaking solitary waves over a fine sand beach. Part II: Numerical simulation, Marine Geology 269 (2010) 119-131.

[29] N. Ahmad, H. Bihs, M. A. Chella, A. Arntsen, Numerical modelling of arctic coastal erosion due to breaking waves impact using REEF3D (2017) ISOPE. Soga.

[30] R. Bakhtyar, D. A. Barry, A. Yeganeh-Bakhtiary, L. Li, J. Y. Parlange, G. C. Sander, Numerical simulation of two-phase flow for sediment transport in the inner-surf and swash zones, Advances in Water Resources 33 (2010) 277-290.

[31] N. G. Jacobsen, J. Fredsøe, J. H. Jensen, Formation and development of a breaker bar under regular waves. part 1: model description and hydrodynamics, Coastal Engineering 88 (2014) 182-193.

[32] A. Roulund, B. M. Sumer, J. Fredsøe, J. Michelsen, Numerical and experimental investigation of flow and scour around a circular pile, Journal of Fluid Mechanics 534 (2005) 351-401.

[33] C. W. Hirt, B. D. Nichols, Volume of fluid method for the dynamics of free boundaries, Journal of Computational Physics 39 (1981) 201-225.

[34] D. C. Wilcox, Turbulence modeling for CFD, third ed., DCW Industries, Inc., La Canada, California, 2006.

[35] D. C. Wilcox, Formulation of the k-ఱ turbulence model revisited, AIAA J. 46 (2008) 2823-2838.

[36] F. Engelund, J. Fredsøe, Sediment transport model for straight alluvial channels, Nord. Hydrol. 7 (1976) 
[37] D. R. Fuhrman, C. Baykal, B. M. Sumer, N. G. Jacobsen, J. Fredsøe, Numerical simulation of wave-induced scour and backfilling processes beneath submarine pipelines, Coastal Engineering 94 (2014) 10-22.

[38] Justesen, J. Fredsøe, R. Deigaard, The bottleneck problem for turbulence in relation to suspended sediment in the surf zone, In: Proc. 20th Int. Conf. on Coastal Engineering (1986) 1225-1239.

[39] B. E. Larsen, D. R. Fuhrman, B. M. Sumer, Simulation of wave-plus-current scour beneath submarine pipelines, Journal of Waterway, Port, Coastal, and Ocean Engineering 142 (2016) 04016003.

[40] C. Baykal, B. M. Sumer, D. R. Fuhrman, N. G. Jacobsen, J. Fredsøe, Numerical investigation of flow and scour around a vertical circular cylinder, Philos. Trans. A Math. Phys. Eng. Sci. 373 (2015) 2033.

[41] C. Baykal, B. M. Sumer, D. R. Fuhrman, N. G. Jacobsen, J. Fredsøe, Numerical simulation of scour and backfilling processes around a circular pile in waves, Coastal Engineering 122 (2017) 87-107.

[42] A. W. Paweł, J. C. G. Verschaeve, G. K. Pedersen, Benchmarking of Navier-Stokes codes for free surface simulations by means of a solitary wave, Coastal Engineering 91 (2014) 1-17.

[43] B. E. Larsen, D. R. Fuhrman, J. Roenby, Performance of interFoam on the simulation of progressive waves, arXiv:1804.01158 [physics.flu-dyn] (2018).

[44] Y. H. Chang, K. S. Hwang, H. H. Hwung, Large-scale laboratory measurements of solitary wave inundation on a 1:20 slope. Coastal Engineering, 56 (2009) 1022-1034.

[45] A. Bayon, D. Valero, Performance assessment of OpenFOAM and FLOW-3D in the numerical modeling of a low Reynolds number hydraulic jump, Environmental Modelling \& Software 80 (2016) $322-335$.

[46] T. Sui, J. Zheng, C. Zhang, D. Jeng, J. Zhang, Y. Guo, R. He, Consolidation of unsaturated seabed around an inserted pile foundation and its effects on wave-induced liquefaction. Ocean Engineering 131 (2017) 308-321.

[47] T. Sui, C. Zhang, Y. Guo, J. Zheng, D. Jeng, J. Zhang, W. Zhang, Three-dimensional numerical model 615 


\section{$616 \quad$ Figure captions}

617 Figure 1 Experimental sketch of Sumer et al. [16]: flow and sediment transport induced by a

618 solitary wave on a sloping bed (unit: meter).

619 Figure 2 Example of the computational mesh used in the present simulation.

620 Figure 3 Breaking solitary wave sequence simulated by the present numerical model: (a) shoaling 621 and wave breaking; (b) runup; (c) rundown and hydraulic jump; (d) trailing wave. Note that this 622 figure is scaled to be clearly seen.

623 Figure 4 Water surface elevation comparison: (a) Toe; (b) Section 1; (c) Section 3; (d) Section 5; 624 (e) Section 8.

625 Figure 5 Bed shear stress comparison: (a) Toe; (b) Section 2; (c) Section 5; (d) Section 6; (e) 626 Section 8.

627 Figure 6 The $x$ variation of the peak value of the bed shear stress (a) during the shoaling and 628 runup stages and (b) during the rundown and hydraulic jump stages.

629 Figure 7 Time variations of the turbulent kinetic energy at different sections computed by the 630 present numerical model: (a) Section 1; (b) Section 2; (c) Section 5; (d) Section 6; (e) Section 8.

631 Figure 8 The $x$ variation of the peak value of turbulent kinetic energy computed by the present numerical model (a) during the shoaling and runup stages and (b) during the rundown and 633 hydraulic jump stages.

634 Figure 9 Sequence of simulated bed profile (red solid line) and water surface (blue dashed line) 635 during wave rundown stage $(t \geq 8 \mathrm{~s})$. Note that this figure is scaled to be clearly seen.

636 Figure 10 Spatial variation of bottom velocity magnitude at the corresponding moment in Fig. 9.

637 Figure 11 Comparisons between computed (lines) and experimental (dots) bed profiles after 638 different number of solitary waves.

639 Figure A.12 Comparison of water surface elevation using different meshes.

640 Figure A.13 Time variations of the computed velocity magnitude at different sections computed 
641 by the present numerical model using different meshes: (a) Toe; (b) Section 1; (c) Section 3; (d) 642 Section 5; (e) Section 8.

643 Figure B. 14 Comparison of wave surface in spatial between numerical and experimental results. 